\title{
Inflammatory Fibroid Polyp Causing Intestinal Obstruction following Restorative Proctocolectomy for Ulcerative Colitis
}

\author{
Cesare Ruffolo $^{a}$ Marco Scarpa $^{b}$ Domenico Bassi ${ }^{a} \quad$ Imerio Angriman ${ }^{a}$ \\ ${ }^{a}$ Clinica Chirurgica I, Department of Surgical and Gastroenterological Sciences, University of Padova, and \\ ${ }^{b}$ Department of Surgery, Veneto Oncological Institute (IOV-IRCCS), Padova, Italy
}

A 44-year-old woman was admitted to our department for intestinal obstruction. Two years earlier the patient had undergone laparoscopic restorative proctocolectomy for steroid-resistant ulcerative colitis with a normal follow-up. At admission she presented with a 3day history of vomiting, cramping abdominal pain and rectal bleeding. The plain supine and erect radiograph of the abdomen (fig. 1) demonstrated some fluid levels with evidence of a mass (arrow) in the pelvic region. A CT scan of the abdomen (fig. 2) showed a 4 -cm roundish mass occupying three-quarters of the intestinal loop proximal to the ileal pouch (arrow). An enteroscopy confirmed the presence of a polypoid sessile lesion with mucosal edema and hyperemia.

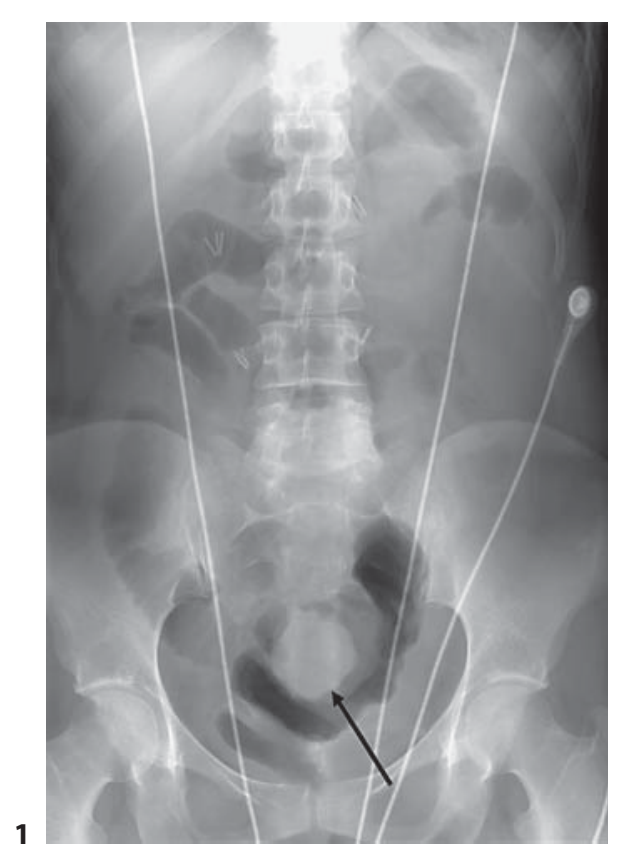

\section{KARGER}

Fax +4161306 1234 E-Mail karger@karger.ch www.karger.com www.karger.com/dsu
Fig. 1. Plain radiograph of the abdomen showing a pelvic mass (arrow).

Fig. 2. CT scan confirming the intestinal lesion (arrow) in the pelvic region.

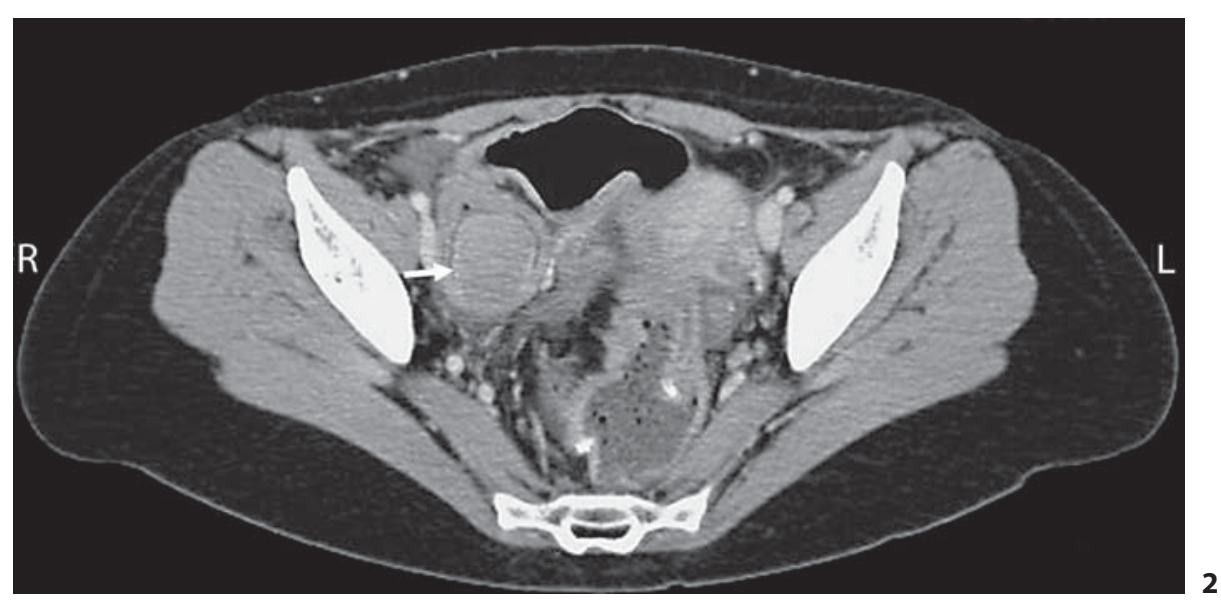

Cesare Ruffolo, MD

IV Unit of Surgery, Regional Hospital Ca' Foncello

Piazza Ospedale 1, IT-31100 Treviso (Italy)

Tel. +39 422322 480, Fax +39422 322 322, E-Mail cruffolo@hotmail.com 
Explorative laparoscopy confirmed the intestinal lesion, causing small bowel intussusception, and resection of the bowel loop was performed. At enterotomy a $3.7 \times$ $3.7 \mathrm{~cm}$ sessile polyp (fig. 3) was noticed. Histology revealed inflammatory fibroid polyp. Even though inflammatory fibroid polyps occurring in the pelvic ileal reservoir after restorative proctocolectomy in ulcerative colitis are rarely described in the literature, these lesions should be taken into account in the differential diagnosis of intestinal obstruction following this type of operation.

Fig. 3. Specimen of bowel loop after enterotomy demonstrating the sessile polyp.

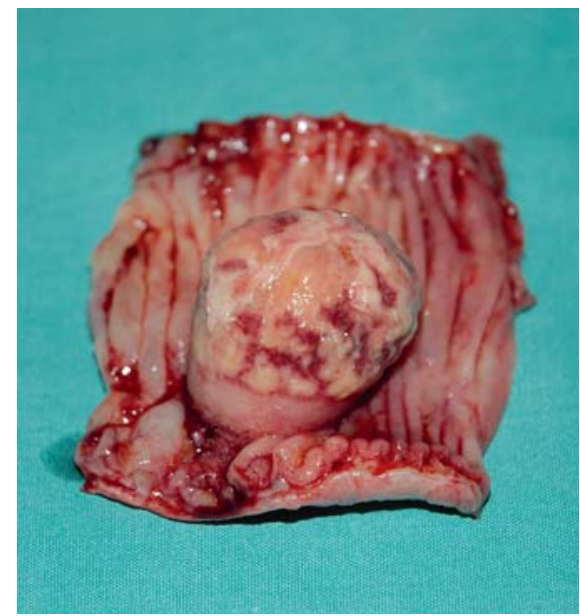

